American Journal of Pharmaceutical Education 2020; 84 (8) Article 7394.

\title{
RESEARCH
}

\section{A Student-Led Elective Provides Quality Improvement Feedback for a Required Compounding Course}

\author{
Emily C. Darst, PharmD, Tanya K. Makhlouf, PharmD, Erin C. Brannick, PharmD, Taylor B. Mitchell, \\ Robert P. Shrewsbury, PhD \\ University of North Carolina at Chapel Hill, Eshelman School of Pharmacy, Chapel Hill, North Carolina \\ Submitted September 21, 2018; accepted February 3, 2020; published August 2020.
}

\begin{abstract}
Objective. To implement an advanced elective compounding course where pharmacy students conduct investigations to improve compounding-related issues that were subsequently evaluated in a required compounding course.

Methods. The elective compounding course required students to engage in self-directed learning, critical thinking, creation and evaluation of laboratory data, and self- and group reflection. Students researched and developed "solutions" to compounded preparation problems, and their solutions were tested in the next iteration of a required compounding course. For example, students in the elective course identified sources of potency variability in a ketoprofen Pluronic organogel (PLO) emulsion preparation. The students identified six variables and executed an investigative action plan. They considered all data collected and proposed a method to reduce potency variation. The recommended solution was implemented in the next offering of a required compounding course and the potency variability results were compared to the previous required course's results.

Results. The mean ketoprofen PLO emulsion potency achieved in the required course prior to implementing the elective course recommendation was $129 \%$ (SD 21\%), $\mathrm{n}=158$. After the recommended change from elective course was implemented, the mean potency was $118 \%$ (SD 21\%), $n=131$.

Conclusion. The teaching methods and activities conducted in the elective course provided students with a deeper level of learning and understanding of compounding science, while providing practical experience in scientific research methodology. The course also provided a cyclic quality improvement feedback mechanism for the required course.
\end{abstract}

Keywords: compounding, potency variability, knowledge retention, quality improvement feedback

\section{INTRODUCTION}

Compounding is a tool used to address patients' needs for personalized medicine. A practicing pharmacist is responsible for understanding the therapeutic activity of a drug product for a given disease state. Many times, however, the drug product is not commercially available in a strength or formulation that meets the patient's personal needs. Therefore, in addition to ensuring appropriate therapy, compounding pharmacists are also responsible for understanding the chemical and biopharmaceutical aspects of the product's formulation. This includes knowledge of how inactive components can be substituted or interchanged to best accomplish the ideal activity of the dosage preparation for the individual patient.

Corresponding Author: Robert P. Shrewsbury, Eshelman School of Pharmacy, University of North Carolina at Chapel Hill, 301 Pharmacy Ln., Chapel Hill, NC 27599-7574. Tel: 919-962-0093. E-mail: bob_shrewsbury@unc.edu.
The art and science of compounding are considered an important knowledge and skill set for pharmacy practice that should be taught and retained in the Doctor of Pharmacy (PharmD) curriculum. ${ }^{1}$ Compounding is taught in pharmacy schools through a variety of required and elective compounding courses, but the curricula are not uniform. ${ }^{2}$ Each pharmacy school is responsible for developing its own compounding curriculum based on many institution-specific factors, and this has led to both strengths and shortcomings in each program's compounding experience. Currently, many pharmacy schools impart only the knowledge and skills necessary for students to read, interpret, and prepare a compounded preparation for a patient. There is minimal instruction on how to create or modify a preparation, and little emphasis on the necessity of an acceptable potent preparation.

A required one-semester compounding course at the Eshelman School of Pharmacy provides instruction to PharmD students during the first professional (P1) year. 


\section{American Journal of Pharmaceutical Education 2020; 84 (8) Article 7394.}

In this course, students are given a formulation record and the necessary ingredients, methods, and equipment to accurately compound a preparation. The students learn proper compounding techniques and acquire the skills to prepare several types of common preparations. Given the limited amount of time allotted, it is only feasible to introduce the general concepts of compounding to the students. The students complete the course with the skills and knowledge of a compounding technician, but not those of a compounding pharmacist.

As the school underwent a curriculum transformation in 2015-6, new elective courses were developed to align with the new mission, vision, and schedule blocks of the curriculum. ${ }^{3}$ We envisioned the creation of a new advanced elective course, The Science of Pharmaceutical Compounding, to move compounding knowledge and skills from a technician level to a pharmacist level. The elective course gave students the opportunity to learn critical skills every compounding pharmacist needs to be successful in such a practice. Typical questions compounding pharmacists encounter every day include: "How might I change the preparation to personalize the prescription for this patient?" "This preparation I compounded is not what I expected. What went wrong? What do I need to change?" or "What new methods or procedures would improve this preparation?" An additional goal of the course was to provide an avenue for improvement of the methods and assessments used in the required compounding course. The third objective, though a tacit objective, was to foster students' retention of compounding skills throughout the PharmD curriculum. ${ }^{4}$

Two of the desired "compounding pharmacist" objectives, to learn compounding skills pharmacists need and the retention of such skills, would be achieved through the course design strategies. The third, improvement of compounding methods and assessments in a required compounding course, was also a realistic objective as the UNC Eshelman School of Pharmacy compounding laboratory has used preparation development and potency analysis (percent of label) as part of its assessment criterion. ${ }^{5,6}$ An extensive potency database is available for preparations analyzed numerous times over several years at the school. However, the required compounding course did not provide the opportunity for students to investigate and understand the intricacies of the preparation development process or to determine the possible sources of potency variability in student compounded preparations.

The compounding faculty envisioned a tangible and useful link between the elective course offered in the P2 and P3 years which would have a limited number of students, and the required P1 compounding course with approximately 160 students per year. The elective course would be a research and development course in which "solutions" to compounding-related questions could be found. Those solutions could then be tested by modifying the compounding exercises used in the required compounding course. As such, the new elective course, The Science of Pharmaceutical Compounding, was designed to create opportunities for student-directed investigations into the following: sources of unintentional potency variation: assessment strategies to determine whether a preparation was correctly or incorrectly compounded; experimental techniques or devices that could be used to analyze alterations in ingredients or modifications in compounding method (ie, how do you determine whether your changes made an improvement?); and recommendations for quality improvement based on generated laboratory data. The objective of this study was to describe the design and implementation of the P2 and P3 elective course and to provide an example of how their solution to a compounding problem was evaluated in the required $\mathrm{P} 1$ course.

\section{METHODS}

An elective compounding course was designed to focus on the development of critical-thinking and problem-solving skills to help students retain and expand their knowledge of compounding science. The elective course was seen as having several characteristics of the learningcentered course described by Albon. ${ }^{7}$ In a learningcentered course, the focus is on knowledge, skills, and values that can be assessable, transferable, and relevant to the learner's pharmacy career. ${ }^{8}$ Faculty members and teaching assistants assume a facilitation role and the students actively learn in a carefully structured, responsive, and guided learning environment. ${ }^{9}$

The content for The Science of Pharmaceutical Compounding course was subdivided into two categories of experiences: research and development experiences (eg, how to select appropriate methods to modify preparations, how to assess changes in compounded preparations); and methods to reduce potency (percent of label) variability. Examples of the first category included: effect of modifying tablet triturate bases on tablet hardness; examining the distribution of particles in semisolids made from different bases; measuring the effect of different powder bases on effervescence; determining the effect of different viscosity enhancing agents on sedimentation rates and volumes; modifying melting points of suppositories using different bases and ingredients; determining the stability of different eutectic mixtures while altering methods of preparation; determining dissolution rates of 


\section{American Journal of Pharmaceutical Education 2020; 84 (8) Article 7394.}

modified-release capsules with different excipients; measuring particle size reduction caused by different contemporary compounding equipment; evaluating the properties of different gelling ingredients; determining the tensile strength in "rectal rockets" made from different combinations of ingredients; developing a lowtemperature method for compounding lollipops; and designing an orodispersible gel film with an appropriate thickness. Examples of the second category (ie, methods to reduce potency variability) involved changing methods of preparation, substituting an ingredient or changing concentrations of ingredients, using different equipment or devices in the compounding process, and determining the applicability of different analytical methods.

The elective course was organized as 16 different laboratory experiences (one experience per week). The elective was offered as two 8-week modules to both P2 and P3 year students in the second semester. These students completed an 8-week rotation of in-school didactic classes and an 8-week immersion experience off campus. Therefore, students were given the opportunity to complete one of the 8-week modules in the P2 year and the other in the P3 year if they chose to do so.

Students met once weekly for four hours. Each week, the course facilitator provided online resources and readings relevant to the posed "compounding issue" students were expected to understand before coming to class. The first part of the class was used by faculty members and teaching assistants to ascertain whether students had completed and understood the pre-class assignments. This was seen as an essential component of the laboratory time because understanding the online material facilitated a student-led discussion that would lead to a subsequent action plan, which would be a significant attempt to resolve the posed compounding issue. The action plan might involve devising a new analysis scheme or method of compounding the preparation, substituting or changing the ratio of excipient ingredients in the preparation, or investigating a completely novel dosage form the students had not compounded in the required compounding course completed in their P1 year. Typically, students would identify four to six variables to investigate, then the investigative work was distributed among the students and carried out in the compounding laboratory. Examples of variable data collected included particle size distribution, pharmaceutical analysis, dissolution analysis, friability testing, sedimentation rates and volumes, microscopic examination, and tensile strength measurements.

After the students carried out their action plan in the laboratory, they discussed the groups' findings and proposed a final recommendation based on all of the students' experiences during the laboratory period. The final recommendation would be incorporated into the next offering of the required course to judge whether the recommendation would indeed lead to an improvement in the issue under investigation. Therefore, the link between the two courses (required and elective) was tangible and served as a quality improvement process within the compounding laboratory.

All students were responsible for completing a laboratory notebook report each week that included their individual notes from the readings and group discussions, documentation of laboratory activities, results, individual analysis data, group analysis data, worksheets, checklists, etc. Students were also evaluated during each class period on their participation in pre-laboratory discussions as the class required participation from all group members, and the success of the group depended on insightful and constructive contributions from every member. The notebook was assessed by the instructor for completeness, accuracy of information, and presentation of thoughts or ideas from the student-based data collected during the experimental portion of the class period. A grading rubric was used to objectively assess the notebook (Appendix 1). Individual student participation in the pre-laboratory discussions was initially determined by peer-assessments based on a five-question rubric (Appendix 2). This was later converted to assessment of student participation conducted by the instructor and based on a three-point scale: one point if present but did not participate; two points if one to two questions or comments were offered; and three points if significant and insightful contributions were made.

The final examination in the 8-week elective course was labeled, "You as the Pharmacist." Each student was given a compounded preparation, the formulation record used to compound the preparation, and a complaint (ie, something was undesirable or problematic about the preparation). The students were to formulate a hypothesis as to the cause of the undesirable aspect and compound a preparation that would resolve the issue. This was an open-book, online examination, and students had to complete the exam on an individual basis so the instructor could assess students' critical problem-solving skills and application of knowledge gained throughout the course.

One objective of the elective course was to provide insights into the sources of potency variability found in preparations compounded in the required compounding course. An example of this process was the Pluronic organogel (PLO) emulsion containing ketoprofen. The formulation record for this assignment is given in Appendix 3. A video demonstrating the compounding procedure is available on the pharmlabs.unc.edu website (Emulsions: Preparation and Stabilization), and the 


\section{American Journal of Pharmaceutical Education 2020; 84 (8) Article 7394.}

analysis method is described on the pharmlabs.unc.edu website (Resources > UV/VIS).

The PLO emulsion was compounded by placing the ingredients in two $10-\mathrm{mL}$ syringes, connecting the syringes with a luer-lock to luer-lock adapter, and repeatedly transferring the ingredients back-and-forth between the syringes. After the preparation was completed, all the emulsion was placed in one $10-\mathrm{mL}$ syringe and aliquots of $1-\mathrm{mL}$ oral syringes were taken from the $10-\mathrm{mL}$ syringe. One 1-mL syringe was used to prepare a sample to determine the ketoprofen concentration in the PLO emulsion using a linearity spectrophotometric assay.

Several years of analytical data from the required compounding course indicated the ketoprofen potency variability of solutions compounded by P1 students could be $60 \%-70 \%$ of the labeled concentration. ${ }^{5}$ A similar potency variation had been reported at another school of pharmacy using a similar PLO preparation. ${ }^{10}$ In addition to the potency variation, visual observations over time by the course instructor had shown many of the PLO preparations "separated or appeared clear" inside the 1-mL oral syringes within 24 to 48 hours after compounding.

The P2 and P3 students in the elective course investigated several scenarios they thought might be responsible for the potency variability and separation of the emulsion. The variables chosen to be investigated were: use a syringe cap instead of Parafilm on the tip of the 10$\mathrm{mL}$ syringes; alter the speed of transfer between $10-\mathrm{mL}$ syringes ( 1 second vs 5 seconds); use different syringe sizes to compound the preparation $(3 \mathrm{~mL}$ vs $10 \mathrm{~mL})$; use a different number of transfers $(5,30,50,100)$; remove or leave air bubbles in the syringes during the transfers; alter total time of 30 transfers; and use different sizes of the connector opening. The possibility of a non-uniform ketoprofen distribution leading to separation within a syringe was investigated by drawing samples from a 10 -mL syringe from the opening, middle, and plunger end of the syringe barrel on day 1 and day 7 and comparing the amount of ketoprofen in each segment. Separation was also visually evaluated by the course instructor. The students compounded their preparations in the same manner as P1 students would in the required pharmacy course and used a PLO emulsion compounded with a mortar and pestle (packaged in an ointment jar) as an analytical and visual observation standard. This method of preparing the standard was suggested by the course instructor.

The final recommendation from the investigation conducted in the elective course was implemented in the subsequent offering of the required compounding course, and the potency variability of P1 students' compounded emulsions was compared to the potency variability of compounded emulsions by P1 students from the previous year (prior to the investigation and findings in the elective course). A Wald z-test for the two means was used to determine a statistical difference in ketoprofen potency as the variance of each population size was known and each population size was greater than 30 . A $p=.05$ was used as the level of significance. Institutional review board approval was deemed unnecessary for this study.

\section{RESULTS}

The greatest reduction in potency variability found in the elective course investigation was replacing the Parafilm on the end of the 10-mL syringes with the luer-lock type syringe cap. This was not a surprise as this step was problematic for many $\mathrm{P} 1$ students when they compounded the emulsion in the required course. Many students had difficulty achieving a tight seal with the Parafilm, whereas the syringe cap would consistently provide a tight seal. There was no evidence of emulsion separation on day 1 vs day 7, either by analytical results or visual observation.

Based on the results, the use of syringe caps was incorporated in the next iteration of the required course, and the potency variability was compared with the results of the previously taught required course. The ketoprofen potency average in the required course before implementing the recommendation (ie, using Parafilm) was $129 \%$ (SD 21\%). After implementing the recommendation (ie, using the luer-lock syringe cap), the potency average was $118 \%$ (SD 21\%). These average potency values were significantly different $(p=.03)$, with more potency accuracy seen in the preparations made using the syringe cap (Table 1). The change in skewness and kurtosis seen in Figure 1 show a shift of values toward the expected potency value of $100 \%$. The skewness values decreased from -0.76 to -1.45 when the elective course implementation was executed, indicating a larger number of students were able to achieve a more accurate potency between the expected potency of $100 \%$ and the observed average potency of $118 \%$ in comparison to the students in the required course who compounded the emulsion before the recommended change was implemented. The kurtosis value also changed from 3.18 to 4.71, indicating a larger number of P1 students were able to achieve a more accurate potency using the recommendation made by the elective course.

Therefore, students were able to compound their PLO emulsion preparations with more accuracy. However, the mean potency was $118 \%$ in the group of students in the required course who followed the recommendation to use syringe caps. The failure to achieve a potency much closer to $100 \%$ indicated the syringe cap was not the only variable significantly affecting the potency of the 
American Journal of Pharmaceutical Education 2020; 84 (8) Article 7394.

Table 1. Comparison of Potency ${ }^{\mathrm{a}}$ of Ketoprofen Achieved by P1 Students in a Required Compounding Course Before and After Implementation of a Recommendation Made by P2 and P3 Students in an Elective Compounding Course

\begin{tabular}{lcc}
\hline & Before Implementation & After Implementation \\
\hline Potency, Mean (SD) & $129 \%(21)$ & $118 \%(21)$ \\
Observations, No. & 158 & 131 \\
Skewness & -0.76 & -1.45 \\
Kurtosis & 3.18 & 4.71 \\
Range & $32.5-188.9$ & $14.8-153.6$ \\
\hline
\end{tabular}

${ }^{\mathrm{a}}$ Potency based on percent of label

ketoprofen in the PLO emulsion. The students had based their recommendation on the highest potency values they had observed in their investigation. There were three other parameters with potency values similar to but slightly lower than the values achieved with the syringe cap: using 1-second transfer times between syringes (vs 5second transfer times); using $3 \mathrm{~mL}$ syringes (vs $10 \mathrm{~mL}$ syringes); and completing 50 transfers between syringes (vs 100 transfers) to finish the preparation. Because students in the elective course moved on to the next week's compounding issue, these additional parameters were not considered, but will be considered in future iterations of the required course.

\section{DISCUSSION}

The profession of pharmacy as a whole has been on a trajectory to emphasize the development of cognitive skills such as critical thinking and the application of knowledge while minimizing the development of students' technical skills. In the compounding arena, both cognitive and technical skills are required for pharmacists to deliver the level of personalized or precision medicine that cannot be provided by commercially available products. As the growth of pharmacogenomics continues to determine appropriate therapies, there will be a more important role for pharmacists to compound the individualized dosage forms that will be required to deliver such therapies. ${ }^{11-13}$

The Science of Pharmaceutical Compounding elective was created to foster a research-based environment with two overarching objectives: provide opportunities for students to think critically, solve problems, and independently acquire learning skills required of pharmacists in a contemporary compounding practice; and provide a mechanism to reduce the potency variability in the preparations students make in the required compounding course. Another incidental objective was to provide a learning approach that would both expand students' understanding of compounding and foster their retention of compounding skills.

The first study objective was achieved through the class structure of the elective course, which added new

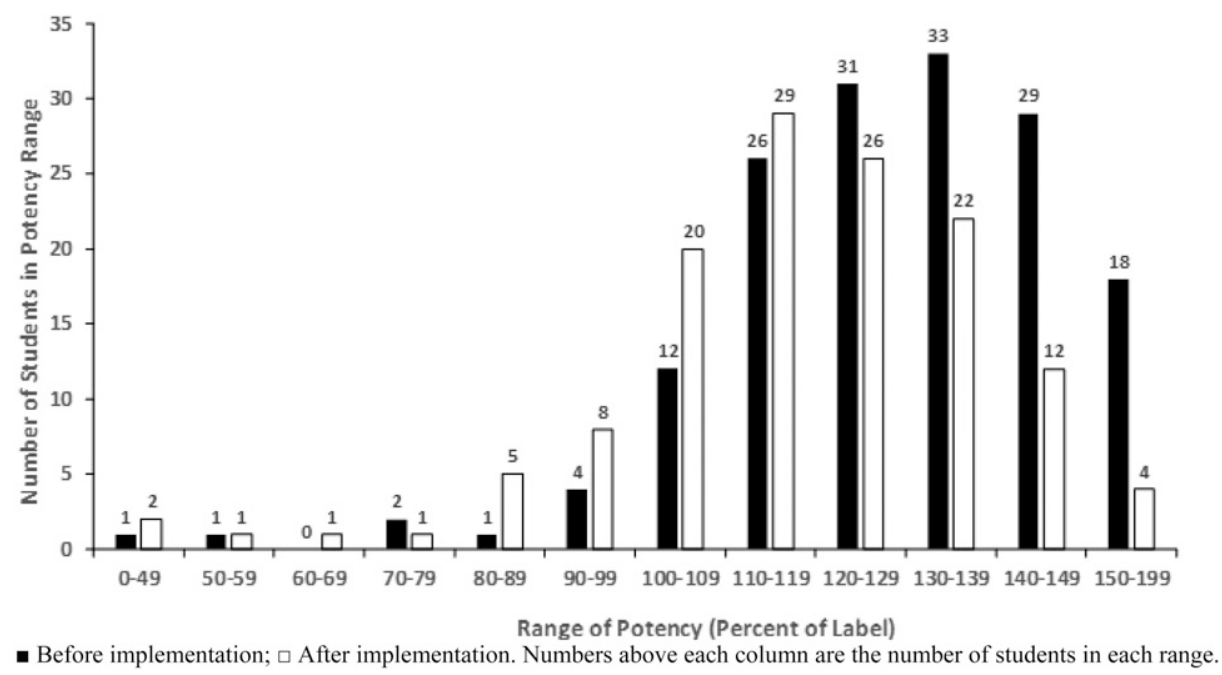

Figure 1. The defined ranges of the potency (percent of label) of ketoprofen in PLO emulsion in a required compounding course before and after implementation of the recommendation from students in an elective compounding course are presented to illustrate the impact of skewness and kurtosis changes. 


\section{American Journal of Pharmaceutical Education 2020; 84 (8) Article 7394.}

elements of learning to the basic set of compounding skills students had previously obtained. Students in the elective course engaged in team-based exploration of compounding as a science and used prior knowledge, as well as readily available resources to better understand various principles of compounding techniques. The "process" of using the scientific method to investigate hypotheses, create action plans, generate data, organize and record results, reflect on the results, and then make a conscious decision regarding what was the most reasonable answer to the hypothesized question embodies all of the critical elements of the objective. These very activities have also been shown to expand and foster students' retention of knowledge in the subject. There is a body of evidence that has shown knowledge acquisition and retention can be enhanced if a course is designed to include elements crucial to the development and practice of metacognition, ${ }^{14-20}$ including critical thinking, self-directed activities, repetition, ${ }^{21-23}$ problem solving, ${ }^{16,18}$ and reflection. ${ }^{24-28}$ In addition, research suggests people become experts in a subject by learning to solve problems that become progressively more complex over time. ${ }^{29}$

The inclusion of higher-order thinking elements prepares the students much more effectively for the role of a compounding pharmacist. The required pharmacy course addresses the knowledge, comprehension, and application aspects of Bloom's Taxonomy. It also begins to introduce the importance of pharmaceutical analysis as students analyze their compounded preparation for potency. ${ }^{30}$ The elective course continues to build on this initial skill set as students comprehend the relevance of pre-class readings related to the posed "compounding problem." Synthesis is also achieved as students develop their own hypotheses and design experiments to address the problem. Lastly, the course promotes reflective evaluation as the students discuss and evaluate data obtained through experimentation and then make a recommendation for addressing the initial problem. By achieving these higher levels of Bloom's Taxonomy, students have been encouraged to engage in deep critical thinking and application of problem-solving skills that can be applied beyond the field of compounding.

The Science of Pharmaceutical Compounding elective course was developed with these elements of learning embedded in the course design. The element of selfdirected learning could be visualized in the creation of action plans. Repeated exposure to the "method" was accomplished by encouraging students to use the scientific method in the testing of hypotheses, critical thinking, and evaluation of the data in the laboratory week after week. Reflection was incorporated by requiring students to complete individual laboratory notebook entries.
Additionally, students reflect on the pre-laboratory discussion, both in creating an action plan and learning how to proceed when confronted with similar compounding issues or problems in the future.

The second objective, to create an educational mechanism to improve potency accuracy outcomes, has not been widely realized in schools of pharmacy. ${ }^{2,5,6} \mathrm{~A}$ survey evaluating the compounding curriculum within pharmacy schools identified a lack of analytical testing in educational compounding laboratories. Most survey respondents cited direct observation as their primary assessment approach, while only a small percentage $(8 \%)$ of institutions used a quantitative method to evaluate student preparations. ${ }^{10}$ Some institutions have attempted to implement analytical testing in the laboratory through changes in course design and assessment. ${ }^{31-37}$ One study in which the accuracy of pharmacy student compounded preparations were evaluated found only $54 \%$ of students prepared the desired potassium permanganate solution within $10 \%$ of the intended concentration. ${ }^{37}$ Students who were unsuccessful in accurately compounding the solution had concentrations ranging from less than $75 \%$ to greater than $200 \%$. In other reports, $16 \%$ to $80 \%$ of students were found to compound their preparations within $10 \%$ of a label on the first attempt. ${ }^{5,6}$ The lower percentages were obtained when students were compounding labor-intensive preparations, such as medication sticks, Pluronic organogels, or troches, while the higher percentages were obtained when students were preparing solutions and suspensions. Incorporating analytical testing of compounded preparations into the pharmacy curriculum gives students a sense of accountability for ensuring their preparations meet the acceptable quality standards before dispensing the preparation to a patient. ${ }^{10}$ A previous study from this laboratory also demonstrated student confidence increased when they were given the opportunity to analyze their own preparations. ${ }^{38}$

A third, though incidental, objective of this study was to provide a learning approach that would both expand pharmacy students' understanding of compounding and foster retention of their compounding skills. In the pharmacy academic compounding community, retention of compounding skills has been the focus of several studies. One study found only $17 \%$ of students were able to compound metoprolol capsules with the required competency grade of $80 \%$ one year after they had compounded the same preparation. ${ }^{39}$ Not only had these students compounded metoprolol capsules the previous year, they had also compounded four additional capsule preparations during the same timeframe. Another report showed $25 \%$ of students had difficulties retaining nonsterile compounding skills for more than one semester. ${ }^{40}$ 


\section{American Journal of Pharmaceutical Education 2020; 84 (8) Article 7394.}

This lack of retention was also evident in compounded sterile preparations, and was addressed by having students complete additional training in their third professional year introductory pharmacy practice experiences. ${ }^{41,42}$ Several other studies support these findings by demonstrating knowledge levels significantly increased immediately following training and/or continuing education courses, but declined to near baseline within four to 10 weeks if no followup training or practice experiences occurred. ${ }^{21,22,43,44}$

Anecdotally, there are three aspects of the cyclic arrangement between the required and elective compounding courses worth mentioning. Retention of compounding knowledge would seem a logical outcome of such a course arrangement but would require another study to prove such an assumption. The expansion of students' understanding of compounding was evident to the course instructor, who was responsible for grading all of the reports. The laboratory reports were organized according to the rubric in Appendix 1. The pre-class readings and discussion were the most revealing sections of a student's understanding of compounding science.

In the first offering, 11 students completed the elective course ( 3 in the first 8 weeks, and 8 in the second 8 weeks). The group sizes were small and the discussions were rich in content. During the second course offering, 35 students completed the elective course, with 15 students in the first 8-week session, and 20 in the second 8week session. In the first 8-week session, the course instructor and teaching staff found it difficult to achieve the same high level of participation as was seen the previous year with the smaller enrollment. During the second 8week session, the class of 20 students was split into two 10 -student groups with separate teaching assistants, and each group operated independently. This restored the desired level of participation and added an unexpected additional interaction between the groups. The two 10student groups "became" a single, larger group, sharing their individual action plans and collected data. This interaction created another layer of collaborative learning and discussion. A group size of 10 students per teaching assistant would be optimum for this type of elective course, and this also establishes a scalable structure as course enrollment continues to expand.

\section{CONCLUSION}

Schools of pharmacy have significant challenges in providing sufficient compounding education to ensure their graduating students are adequately prepared to be compounding pharmacists in a rapidly evolving health care environment. The challenges to compounding itself are continuously impacted by technologies such as 3D printing, ${ }^{45-47}$ pharmacogenomics, ${ }^{11-13}$ and advances in biotechnology pharmaceuticals. Compounding provides totally personalized medications for patients. There is not and will not be a "one size fits all" answer in any compounding situation, so students must have the ability to critically think and solve problems to provide the personalized support those patients need. Completing The Science of Pharmaceutical Compounding elective, which includes discussing and investigating solutions of realistic compounding problems, enables our students to think more critically about situations they will encounter in their careers and to develop a method that will enable them to propose rational solutions to these issues.

\section{REFERENCES}

1. Martin KS, McPherson TB, Fontane PE, et al. Independent community pharmacists' perception on compounding in contemporary pharmacy education. Am J Pharm Educ. 2009;73(3):Article 54

2. Shrewsbury R, Augustine S, Birnie C, et al. Assessment and recommendations of compounding education in AACP member institutions. Am J Pharm Educ. 2012;76(7):Article S9.

3. Roth MT, Mumper RJ, Singleton SF, et al. A renaissance in pharmacy education at the University of North Carolina at Chapel Hill. North Carolina Medical Journal. 2014;75(1):48-52.

4. Yoo KY, Shrewsbury RP. Effect of course structure on the accuracy of nonsterile compounded preparations. Am J Pharm Educ. 2018;82(9):Article 6463.

5. Roark AM, Anksorus HN, Shrewsbury RP. Long-term results of an analytical assessment of student compounded preparations. Am J Pharm Educ. 2014;78(9):Article 164.

6. Alford EL, Shrewsbury RP. Impact of required versus optional remake of a preparation on pharmacy students' compounding accuracy. Am J Pharm Educ. 2013;77(4):Article 73.

7. Albon SP. A learning-centered course in pharmaceutical analysis. Am J Pharm Educ. 2004;68(5):Article 114.

8. Hubball H, Poole GD. Learning-centered education to meet the diverse needs and circumstances of university faculty through an 8month program on teaching and learning in higher education. Int $J$ Acad Dev. 2004;8:11-24.

9. Barr RB, Tag J. From teaching to learning: a new paradigm for undergraduate education. Change. 1995;Nov/Dec:13-25.

10. Pignato A, Birnie CR. Analysis of compounded pharmaceutical products to teach the importance of quality in an applied pharmaceutics laboratory course. Am J Pharm Educ.

2014;78(3):Article 61.

11. Allen LV, Jr. Biotechnology, nanotechnology, and pharmacogenomics and pharmaceutical compounding, part 1. Intl J Pharm Compound. 2015;19(1):38-40.

12. Allen LV, Jr. Biotechnology, nanotechnology, and pharmacogenomics and pharmaceutical compounding, part 2. Intl $J$ Pharm Compound. 2015;19(4):280-287.

13. Joseph D, Daron B, Allen VL, Jr. Pharmacogenomics: precision pharmacy in 503A compounding. Intl J Pharm Compound. 2018;22(2):95-107.

14. Budzinski JW. An online knowledge resource and questionnaires as a continuing pharmacy education tool to document reflective learning. Am J Pharm Educ. 2012;76(5):Article 82. 


\section{American Journal of Pharmaceutical Education 2020; 84 (8) Article 7394.}

15. Walpola RL. Evaluating the effectiveness of an educational intervention to improve the patient safety attitudes of intern pharmacists. Am J Pharm Educ. 2017;81(1):Article 5.

16. Persky AM, Robinson JD. Moving from novice to expertise and its implications for instruction. Am J Pharm Educ. 2017;81(9):Article 6065.

17. Tanner KD. Promoting student metacognition. CBE Life Sci Educ. 2012;11(2):113-120.

18. Medina MS, Conway SE, Davis-Maxwell TS, et al. The impact of problem-solving feedback on team-based learning case responses. Am J Pharm Educ. 2013;77(9):Article 189.

19. Schneider EF, Castleberry AN, Vuk J, et al. Pharmacy students' ability to think about thinking. Am J Pharm Educ. 2014;78(8):Article 148.

20. Lonie JM, Desai KR. Using transformative learning theory to develop metacognitive and self-reflective skills in pharmacy students: a primer for pharmacy educators. Curr Pharm Teach Learn.

2015;7(5)669-675.

21. Broomfield R. A quasi-experimental research to investigate the retention of basic cardiopulmonary resuscitation skills and knowledge by qualified nurses following a course in professional development. J Adv Nurs. 1995:23:1016-1023.

22. Valdez CA, Thompson D, Ulrich $\mathrm{H}$, et al. A comparison of pharmacy students' confidence and test performance. Am J Pharm Educ. 2006:70(4);Article 76.

23. Popovich NG, Rogers WJ. An assessment of pharmacy student confidence in learning. Am J Pharm Educ. 1987;51:17-13.

24. Steuber TD, Janzen KM, Walton AM, et al. Assessment of learner metacognition in a professional pharmacy elective course. $\mathrm{Am}$ $J$ Pharm Educ. 2017;81(10):Article 6034.

25. Van Vliet E, Winnips JC, Brouwer N. Flipped-class pedagogy enhances student metacognition and collaborative-learning strategies in higher education but effect does not persist. CBE Life Sci Educ. 2015;14(3):1-10.

26. Schellenberg S, Negishi M, Eggen P. The effects of metacognition and concrete encoding strategies on depth of understanding in educational psychology. Teach Educ Psychol. 2011;7(2):17-24

27. Turan S, Demirel O, Sayek I. Metacognitive awareness and selfregulated learning skills of medical students in different medical curricula. Med Teach. 2009;31(10):e477-e483.

28. Tsingos-Lucas C, Bosnic-Anticevich S, Schneider CR, et al. The effect of reflective activities on reflective thinking ability in an undergraduate pharmacy curriculum. Am J Pharm Educ.

2016;80(4):Article 65.

29. Ytterberg SR, Harris IB, Allen SS, et al. Clinical confidence and skills of medical students: Use of an OSCE to enhance confidence in clinical skills. Acad Med. 1998;73:S103-S105.

30. Adams NE. Bloom's taxonomy of cognitive learning objectives. J Med Libr Assoc. 2015;103(3):152-153.
31. Capehart KD. A laboratory exercise in capsule making. $A m J$ Pharm Educ. 2008;72(5):Article 119.

32. Hinkle AR, Newton GD. Compounding in the pharmacy curriculum: beyond the basics. Int J Pharm Compd. 2004;8:181-185. 33. Shrewsbury RP, Deloatch KH. Accuracy in prescriptions compounded by pharmacy students. Int J Pharm Compd. 1998;2(2):139-142.

34. McGill JE, Holly DR. Integration of pharmacy practice and pharmaceutical analysis: quality assessment of laboratory performance. Am J Pharm Educ. 1996;60(Winter):370-374. 35. Almoazen H, Samsa AC, May CN. Why analytical testing is needed in pharmaceutical compounding. Am J Pharm Educ. 2010;74(2):Article 32.

36. Birnie CR, Zhao F, Budukh PP, Pankaskie MC. Enhancing student awareness of the quality aspects of compounded pharmaceutical preparations. Am J Pharm Educ. 2008;72(3):Article 72.

37. Kadi A, Francioni-Proffitt D, Hindle M, et al. Evaluation of basic compounding skills of pharmacy students. Am J Pharm Educ. 2005;69(4):Article 69.

38. Jih JS, Shrewsbury RP. Student self-analysis of their nonsterile preparations and its effect of compounding confidence. Am J Pharm Educ. 2018;82(10):Article 6473.

39. Eley JG, Birnie C. Retention of compounding skills among pharmacy students. Am J Pharm Educ. 2006;70(6):Article132.

40. Mudit M, Alfonso LF. Analytical evaluation of the accuracy and retention of compounding skills among PharmD students. Am J Pharm Educ. 2017;81(4):Article 64.

41. Dennis VC, Owora AH, Kirkpatrick AE. Comparison of aseptic compounding errors before and after modified laboratory and introductory pharmacy practice experiences. Am J Pharm Educ. 2015;79(10):Article 158.

42. Cretton-Scott E, Cruthirds D, Coward L. Incorporation of handson sterile technique instruction in an introductory pharmacy practice experience. Am J Pharm Educ. 2015;79(2):Article 28.

43. Tippett J. Nurses' acquisition and retention of knowledge after trauma training. Accident Emerg Nurs. 2004; 12:39-46.

44. Casebeer L, Kristofco RE, Strasser S, et al. Standardizing evaluation of online continuing medical education; physician knowledge, attitudes, and reflection on practice. J Continuing Educ Health Professionals. 2004:24:68-75.

45. Allen LV, Jr. Basics of Compounding: 3D printing - pharmacy applications, part 1. Intl J Pharm Compound. 2017;21(2):

127-130.

46. Allen LV, Jr. Basics of Compounding: 3D printing - pharmacy applications, part 2. Intl J Pharm Compound. 2017;21(3):215-220.

47. Allen LV, Jr. Basics of Compounding: 3D printing - pharmacy applications, part 3: compounding, formulation considerations, and the future. Intl J Pharm Compound. 2017;21(4):293-298. 


\section{American Journal of Pharmaceutical Education 2020; 84 (8) Article 7394.}

\section{Appendix 1. Lab Notebook Rubric Used to Evaluate Students' Notebook Each Week}

Documentation should strive to be complete, logical, detailed, relevant, organized, concise, and legible. Individual sections will be graded as follows (point value shown in parentheses).

\section{Objectives (1)}

Clear statement of question the module is addressing. Outline achievable parameters to be completed within the lab period.

\section{Pre-Class Readings (3)}

Thoughtful reflection on important points from the assigned readings: What was new to you? What was interesting to you? What caught your attention?

Pre-Class Discussion (2)

Notes taken during discussion that expand on relevant points or parameters that might be included in the Action Plan.

Action Plan (2)

Clearly articulate plan for today's lab. Describe goal and rationale for the plan.

\section{Lab Notes (3)}

Completely and concisely detail what was performed in lab: activities conducted, equipment utilized, operational parameters, ingredient specifications

\section{Analysis (2)}

Describe how analysis was performed: record all analytical data.

Group Results (2)

Collect and document results from all students: tabulate data, create trend analysis (if appropriate).

Discussion (2)

Address original problem and if the hypothesized solution was successful; determine if group data suggested alternative solutions. Identify remaining questions and next steps.

Final Recommendations (2)

Offer viable advice to optimize the formulation

Copies of Relevant Documents (1)

\section{Appendix 2. The Initial Student Evaluation Form Used in the Elective Course for Class Participation}

Your participation grade consists of 15 possible points each week:

5 points for submitting your evaluation form each week

10 possible points from your peers' evaluation of your participation.

Evaluating peers: Be thoughtful and honest in your evaluations. The course is based on productive participation in the group discussions.

Each attribute will be worth a possible 2 points:

2 points $=$ Performed well; excellent participation

1 point $=$ Performed adequately

0 points $=$ Unsatisfactory 
American Journal of Pharmaceutical Education 2020; 84 (8) Article 7394.

Attributes

Preparedness

Contribution

Quality of Contribution

Ability to Respond

Creative Discussion
Considerations

Points

Was the student prepared for class today? Was it evident that they had completed the assigned readings/videos prior to class?

Did the student actively participate in the group discussions?

Were the student's contributions useful, constructive, and relevant to the group?

Was the student able to respond to questions when asked directly?

Was the student able to have a creative discussion involving viewpoints differing from their own?

\section{Appendix 3. Formulation Record for Ketoprofen in a PLO Emulsion}

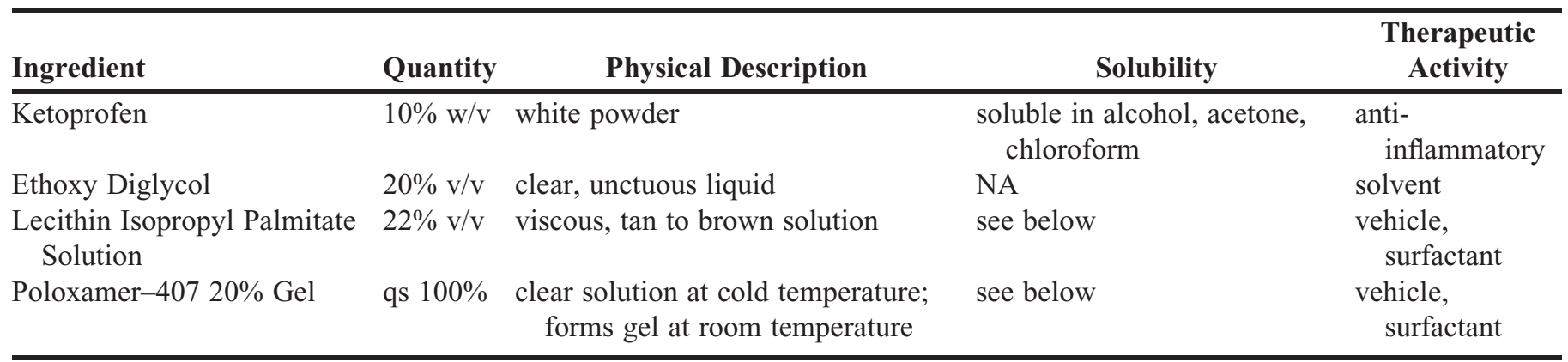

Additional Information:

Lecithin can be derived from eggs but is derived mostly from soybeans. Soybean lecithin contains palmitic, stearic, palmitoleic, oleic, linoleic, linolenic, and arachidonic acids. It is used as a natural surfactant and emulsifier. Lecithin Isopropyl Palmitate Solution contains soybean lecithin $10 \mathrm{~g}$, isopropyl palmitate $10 \mathrm{~g}$, and sorbic acid $0.2 \mathrm{~g}$.

Poloxamer-407 (Pluronic F-127) is one of a series of polymers known as Poloxamers. They are used as nonionic surfactants. Poloxamer-407 is more soluble in cold temperatures (ie, reverse thermal solubility). Solutions should be refrigerated until use since it will gel at room temperature. Poloxamer-407 20\% Gel is Poloxamer-40720 g, potassium sorbate $0.2 \mathrm{~g}$, qs to $100 \mathrm{~mL}$ with Purified Water.

Example Calculations:

Equipment Required:

Class III prescription balance

plastic $10 \mathrm{~mL}$ luer-lock syringes

luer-to-luer syringe connector

luer-to-oral syringe adapter

$1 \mathrm{~mL}$ oral syringes with caps

syringe box

Method of Preparation:

Accurately weigh the ketoprofen in a weigh boat.

Add the ethoxy diglycol to the ketoprofen in the weigh boat and dissolve the powder.

Transfer the mixture into a $10 \mathrm{~mL}$ syringe after wrapping the tip with Parafilm. Use lecithin isopropyl palmitate solution to rinse the weigh boat and help quantitatively transfer the ketoprofen into the syringe.

Carefully remove air from the syringe and determine the volume of Poloxamer gel needed. 


\section{American Journal of Pharmaceutical Education 2020; 84 (8) Article 7394.}

Transfer the appropriate volume of Pluronic gel into another $10 \mathrm{~mL}$ syringe using the luer-to-oral adapter.

Remove all air from the syringe.

Attach the luer-to-luer syringe connector to the two 10-mL syringes and transfer the emulsion back-and-forth between the syringes until well mixed.

Package in an appropriate container.

Description of Finished Product: White to yellow-white emulsion with lotion consistency

Quality Control Procedures:

Content analysis

Final product weight

Packaging Container: Package in appropriate container

Storage Requirements: Store at room temperature: if stored at cold temperature, the Poloxamer gel will liquefy.

Beyond-Use Date Assignment:

USP $<795>$ Guidelines: Water containing topical or semisolid formulations. (Note: Potassium sorbate is a mold and yeast inhibitor). Assign 30 days.

Label Information: External Use Only

Source of Recipe:

Literature Information: 